\title{
OS DESAFIOS E AS POSSIBILIDADES DO USO DAS FERRAMENTAS TECNOLÓGICAS NO CONTEXTO DA PANDEMIA EM INSTITUIÇÕES ESCOLARES
}

\author{
Andreia Aparecida de Sales Basílio' ${ }^{1}$ \\ Benedita Paulina da Silva ${ }^{2}$ \\ Josedelma Martins Pinheiro da Silva Costa ${ }^{3}$ \\ Onezima Constância de Oliveira ${ }^{4}$
}

RESUMO: Este artigo pretende refletir sobre "Os desafios e as possibilidades do uso das ferramentas tecnológicas no contexto da pandemia em instituições escolares". Por conta do contexto da pandemia causada pela contaminação da COVID-I9, as instituições escolares decidiram permanecer, com o ensino remoto. Sendo assim, é necessário que as instituições escolares realizem capacitação com os professores, com o objetivo de discutir caminhos e possibilidades de organização do trabalho pedagógico por meio dos recursos tecnológicos. Esse momento de reflexão é fundamental para que os professores possam encontrar estratégias de enfrentamento dos desafios presentes. Desse modo, professores, precisam conhecer as contribuições das ferramentas digitais e os desafios que a comunidade escolar vivência nesse momento delicado, deve se preocupar com a escolarização dos alunos com necessidades educacionais especiais, assim a escola cumpre seu compromisso social com todos os educandos.

Palavras-chave: Ferramentas tecnológicas, Pandemia, Instituições escolares.

\section{INTRODUÇÃO}

Este artigo tem como temática: Os desafios e as possibilidades do uso das ferramentas tecnológicas no contexto da pandemia em instituições escolares, sendo que essa temática foi escolhida para possibilitar a aprendizagem interdisciplinar e, também, para que possa consolidar uma consciência a respeito da inclusão escolar dos alunos com deficiência

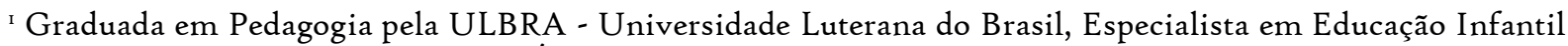
e Especial pela FAE - Faculdade das Águas Emendadas.

${ }^{2}$ Graduada em Pedagogia pela FACIBRA - Faculdade de Ciências de Wenceslau Braz, Graduada em Letras pelo UNIVAG - Centro Universitário, Especialista em Educação Infantil e Especial pela UCAM Universidade Cândido Mendes.

3 Graduada em Pedagogia pela Faculdade Afirmativo, Especialista em Educação Infantil pelo IESMIG Instituto de Ensino Superior de Minas Gerais.

${ }^{4}$ Graduada em Pedagogia pelo Centro Universitário Cândido Rondon, Especialista em Educação Infantil pela FAUC - Faculdade de Cuiabá.
} 
na escola pública que oferta educação básica.

A realização deste trabalho pretende desenvolver as seguintes competências nos profissionais de pedagogia: conhecer os conteúdos das áreas específicas; refletir sobre os direitos do público-alvo da educação especial; refletir sobre possibilidades de ações pedagógicas a serem desenvolvidas em espaço escolar a partir de recursos tecnológicos.

\section{DESENVOLVIMENTO}

A aprendizagem digital está substituindo cada vez mais os métodos educacionais tradicionais todos os dias. O aprendizado digital em sala de aula varia desde o simples uso de um tablet em vez de papel até o uso de softwares e equipamentos complexos em vez de uma simples caneta.

Enquanto não houver uma ferramenta que promova a construção do conhecimento, facilite a análise da informação e transforme a tecnologia em ferramentas de pensamento, esse salto será apenas uma atualização de equipamentos.

As TIC têm um potencial imenso para desenvolver inteligência nos alunos, mas na maioria das escolas, estamos restringindo sua eficácia de tal forma que, não apenas ajudando, mas os está inibindo. Você pode realmente falar sobre o progresso se for além quadro de giz tradicional, para a superfície sintética branca e, em seguida, para o quadro digital interativo, quando a única coisa que está mudando é a superfície de escrita? Possivelmente não. Escrever em um processador de texto é diferente de escrita manual ou é apenas mais fácil? TIC são uma ferramenta, não uma solução (THOMPSON, 20I0).

No Brasil, no que diz respeito à legislação de educação inclusiva, o MEC emitiu o documento "Política Nacional de Educação Especial na Perspectiva da Educação Inclusiva" em 2014 (BRASIL, 2014), cuja missão é orientar o funcionamento e a organização da educação como "especial" Com base em uma educação diversificada. Este documento aponta que a educação especial consiste em um modelo de ensino que oferece atendimento educacional especial aos alunos por meio da disponibilização de recursos e serviços e orientações relacionadas à utilização desses recursos no processo de ensino dos cursos regulares de ensino (BRASIL, 2014). Na perspectiva da inclusão, ao se reorganizar o sistema educacional, há um novo modelo de escola e um novo conceito de formação de professores, que exige que 
os professores estejam preparados para atuar em um ambiente escolar baseado na diversidade.

Para desenvolver eficazmente a sua prática pedagógica, necessita de analisar as diferenças pedagógicas existentes. Trata-se de uma abordagem inovadora, ao contrário da cultura escolar tradicional que até então era efetiva, seletiva e repulsiva, agora se ajustou a uma forma homogeneizada de ensino. Portanto, é necessário garantir que estratégias, serviços e recursos adequados e adaptados sejam adotados para aceitar as características educacionais dos alunos que necessitam de AEE (GIROTO; POKER, OMOTE; 2012).

Giroto, Poker e Omote (2012) apontaram que o uso de TDIC é entre as mudanças relevantes que professores e escolas precisam incorporar A formação educacional é propícia para a aprendizagem geral dos alunos, mais especificamente, os alunos com deficiência incluem o recurso aceito pela sala de recursos multifuncionais é denominado Tecnologia Assistiva. Para entender melhor seus benefícios. Dentre as ferramentas de tecnologia assistiva disponíveis nos seguintes sites: o laptop na sala de referência multifuncional do Ministério da Educação Sintetizador de voz Braille materiais didáticos; software usado Comunicação alternativa; áudio e Língua Brasileira de Sinais-LIBRAS, pode promover o acesso ao currículo (GIROTO; POKER; OMOTE, 20I2).

Em relação à atuação dos professores na formação profissional, estes profissionais precisam entender, entender e entender como promover ações de educação inclusiva no ambiente escolar. Mas isso é formação profissional sólida requer investimento fornece as habilidades necessárias para envolver os professores neste processo métodos educacionais, propõem possibilidades teóricas e metodológicas que podem mudar essa realidade. Essas tecnologias ajudam a integrar um conjunto de mudanças na educação que permitem aos alunos alcançar seus objetivos sugeridos e conteúdo de aprendizagem, como plano de ensino.

A pandemia COVID-ıg fechou escolas no Brasil, ameaça à saúde pela Covid-ı́, trouxe uma mudança repentina para a educação e responsabilidades com o cuidado criou um ambiente estressante e exigente para trabalho do professor. As pessoas estão principalmente preocupadas com os seguintes benefícios: Professores durante a pandemia e sua capacidade de fornecer orientação o controle remoto foi bem-sucedido, os professores também estão certos eles estão dispostos a voltar para a sala de aula quando a escola puder ser reaberta. 
Contudo, mais preocupante é a previsão de um grande número de perdas de aprendizagem Possibilidade para alunos e acesso diferenciado a tecnologia e suporte e estudar em casa agrava a lacuna de desempenho de longo prazo desenvolver-se ao longo de rotas étnicas e socioeconômicas.

Embora as TIC tenham direta ou indiretamente se tornado parte do trabalho diário a realidade da escola e de muitos professores e alunos, seu uso na escola durante a pandemia, em vez de reuniões cara a cara entre eles estão os seguintes desafios: a infraestrutura das casas de professores e alunos; tecnologia usada; acesso do aluno (ou falta) à Internet; este treinamento dos professores para planejar e executar atividades online.

A escola precisa ser organizada para usar tecnologia digital. Essa migração produziu uma mudança na prática, o método de ensino presencial da plataforma de aprendizagem virtual, aprendizagem à distância denominada. Existem muitos motivos que tornam a tecnologia um aspecto básico da aprendizagem escolar, quer queiramos ou não, a tecnologia está em toda parte; para que nossos alunos sobrevivam na educação superior, eles devem entender a tecnologia.

Os alunos são obrigados a fazer isso e estão constantemente interagindo com a tecnologia fora da sala de aula. As crianças adoram interagir e aprender por meio da tecnologia agora $\mathrm{faz}$ parte de suas vidas. $\mathrm{O}$ novo professor pediu para fazer isso. $\mathrm{O}$ movimento técnico foi implementado na educação superior e em outros trabalhos profissionais. Para novos professores, a tecnologia é considerada uma condição necessária do ambiente de aprendizagem.

As crianças são nativas digitais e entendem de tecnologia melhor do que a maioria dos adultos. Tornou-se uma parte indispensável de suas vidas, por isso tornou-se a maneira mais fácil de aprender. Participar da tecnologia em sala de aula não apenas os ajuda a aprender melhor, mas também adquire habilidades multitarefa. Hoje, eles mal sabem como aprender. Esse conhecimento é muito importante, porque sem ele, eles ficarão muito atrás do mundo real.

As crianças podem aprender em seu próprio ritmo. Nós sabemos porque com muitos anos de experiência, as crianças podem aprender em seu próprio ritmo, mas às vezes é difícil fazer em salas de aula tradicionais. Com a integração da tecnologia na educação, as 
crianças têm a capacidade de diminuir o ritmo e voltar à escola, conceito, crianças mais avançadas podem seguir em frente.

O professor também ajuda as crianças a melhorar seu nível pessoal. Com a tecnologia, não há restrições. Pode acessar outro As informações fora do livro fornecem aos alunos muitos métodos de aprendizagem diferentes um conceito. Os professores podem criar maneiras criativas de ensinar seus alunos mantenha-os envolvidos. A tecnologia mudou o ambiente de aprendizagem torne o aprendizado mais prático, sendo que as escolas em todo o país têm renda para crianças de todos os tipos nem sempre obtêm os recursos de que precisam, a implementação de tecnologia nas escolas pode ajudar a eliminar essa lacuna.

A tecnologia tem o poder de melhorar o relacionamento entre si professora e aluno. Quando os professores integram a tecnologia de maneira eficaz na área de assunto, eles se transformam em consultores, especialistas conteúdo e treinador. A tecnologia ajuda a tornar o ensino e a aprendizagem mais significativo e interessante. Os alunos também podem colaborar com seu próprio pessoal Colegas usam tecnologia. Muitos recursos: computadores, tablets e outras formas, a tecnologia traz aos professores alguns recursos que não estão neste livro, eles não deixam os alunos participarem de novos recursos e novos aplicativos interessantes, mas eles têm outras maneiras de ensinar materiais aos alunos. Cada criança aprende de forma diferente, a tecnologia também pode ajudá-lo, a tecnologia envolve as crianças, está é uma geração considerada de aprendiz de tecnologia.

Os alunos aprendem melhor sendo mais interativos, e a tecnologia é o que os ajuda a fazer isso. As crianças diversas vezes lutam para se manter concentradas na tarefa ou interessadas e, com recursos para ajudar o professor, podem manter o foco e aprender mais rápido.

A tecnologia é imprescindível para ter sucesso fora da educação primária e secundária. A tecnologia é um conceito essencial para aprender, como ela muda tão rapidamente, é melhor que as crianças aprendam sobre ela mais cedo. É a parte principal de todos os setores e não há como contornar isso. A tecnologia significa mais do que apenas aprender habilidades básicas de computação, se tornou parte de todos os aspectos de nossas vidas hoje. 
Desse modo torna-se um meio facilitador para o processo de inclusão, para a equiparação de oportunidades a participação e a independência das pessoas com deficiência nos diversos ambientes da sociedade. Na perspectiva da educação inclusiva, esta tecnologia é voltada a favorecer a participação do/a aluno/a com deficiência nas diversas atividades do cotidiano escolar, vinculadas aos objetivos educacionais.

De acordo com Lauand \& Mendes (2008), a Tecnologia Assistiva assume um papel importantíssimo para garantir a aprendizagem dos/as alunos/as, por necessitarem dela para toda a sua educação ou pelo menos para uma boa parte dela. Sendo que a Tecnologia Assistiva utilizada no contexto educacional se tornando um meio facilitador no processo de ensino-aprendizagem dos discentes com deficiência.

Para Bersch (2006, p. 92): "a aplicação da Tecnologia Assistiva na educação vai além de simplesmente auxiliar o aluno a fazer tarefas pretendidas. Nela, encontramos meios de o aluno ser e atuar de forma construtiva no seu processo de desenvolvimento". Portanto, busca-se mostrar a relevância que essas tecnologias têm e a sua contribuição para o ensino aprendizagem das pessoas com deficiência.

É necessário que os gestores e docentes tenham o conhecimento acerca da dimensão dos recursos da TA uma vez que representam possibilidades e novos caminhos no processo de ensino-aprendizagem. "As pessoas com deficiências só perdem quando os profissionais não são capazes de lhes fornecer as técnicas, estratégias ou ferramentas que as ajudariam a lidar com seus problemas" (KAUFFEMAN, 2007, p. I2), bem como preparar discentes, com intuito de que estes possam adaptar matérias pedagógicas e de acessibilidade e utilizar recursos da tecnologia para promover o rompimento de barreiras buscando alternativas que viabilize a inclusão escolar.

A Tecnologia Assistiva (TA) é composta de recursos e serviços. O recurso é o equipamento utilizado pelo aluno, e que lhe permite ou favorece o desempenho de uma tarefa. E o serviço de TA na escola é aquele que buscará resolver os "problemas funcionais" desse aluno, encontrando alternativas para que ele participe e atue positivamente nas várias atividades do contexto escolar (BERSCH, 2006).

Diante dos novos questionamentos acerca da temática da Tecnologia Assistiva no ambiente educacional, ou seja, reflexões perante a formação continuada dos professores, do 
papel das políticas públicas, a disponibilização dos recursos necessários para serem utilizados, conforme as especificidades dos estudantes e não somente que estes recursos sejam disponibilizados, mas que haja fiscalização de modo a garantir que estes estejam sendo utilizados para contribuir no processo de ensino aprendizagem das pessoas com deficiência. Portanto, busca-se mostrar a relevância que essas tecnologias têm e a sua contribuição para o ensino aprendizagem das pessoas com deficiência.

É necessário também que os gestores e docentes conheçam a dimensão dos recursos da TA que representam possibilidades e novos caminhos no processo de ensinoaprendizagem. "As pessoas com deficiências só perdem quando os profissionais não são capazes de lhes fornecer as técnicas, estratégias ou ferramentas que as ajudariam a lidar com seus problemas" (KAUFFEMAN, 2007, p. I2). Faz-se necessário preparar discentes, com intuito de que estes possam adaptar matérias pedagógicas e de acessibilidade e utilizar recursos da tecnologia para promover o rompimento de barreiras buscando alternativas que viabilize a inclusão escolar.

A Tecnologia Assistiva (TA) é composta de recursos e serviços. O recurso é o equipamento utilizado pelo aluno, e que lhe permite ou favorece o desempenho de uma tarefa. E o serviço de TA na escola é aquele que buscará resolver os "problemas funcionais" desse aluno, encontrando alternativas para que ele participe e atue positivamente nas várias atividades do contexto escolar (BERSCH, 2006, p. 283).

Surgem novos questionamentos acerca da temática da Tecnologia Assistiva no ambiente educacional, ou seja, reflexões perante a formação continuada dos professores, do papel das políticas públicas, a disponibilização dos recursos necessários para serem utilizados, conforme as especificidades dos estudantes e não somente que estes recursos sejam disponibilizados, mas que haja fiscalização de modo a garantir que estes estejam sendo utilizados para contribuir no processo de ensino aprendizagem das pessoas com deficiência.

\section{CONCLUSÃO}

O surgimento do coronavírus causou algumas mudanças em nossas vidas, no que diz respeito à educação, mostrou o que vimos discutindo e pesquisando há muito tempo: a 
educação precisa de uma auto-reforma.

O ensino baseado em conteúdo não tem mais lugar na sociedade em que vivemos. $\mathrm{Na}$ fase pós-pandemia, é necessário trabalhar em conjunto para superar o ensino baseado na transmissão, no falar-ditar do mestre (SILVA, 2002), e tentar considerar o potencial da tecnologia de redes digitais e estimular a inovação em outros métodos e práticas.

Durante a pandemia, entrar no caos faz parte de nossas vidas diárias, mas o caos pode tornar a criação possível, e pensar é passar pelo caos e criar áreas de possibilidade e potencial.

Deste modo, as reflexões e a experimentação da educação em tempos de COVID19, como caos, desdobraram-se esperando encontrar ressonâncias para podermos, juntos, lutar por políticas públicas de acesso à internet para todos e por outras educações.

\section{REFERÊNCIAS BIBLIOGRÁFICAS}

BRASIL. Política nacional de educação especial na perspectiva da educação inclusiva. MEC/SECADI, 2014. Disponível em <http://portal.mec.gov.br >. Acesso em 02/07/2021.

BERSCH, R. Tecnologia assistiva e educação inclusiva. In: Ensaios Pedagógicos. Brasília: SEESP/MEC, p. 89-94, 2006.

GIROTO, C. R. M.; POKER, R. B.; OMOTE, S. Educação especial, formação de professores e o uso das tecnologias de informação e comunicação: a construção de práticas pedagógicas inclusivas. In: GIROTO, C. R. M.; POKER, R. B.; OMOTE, S. As tecnologias nas práticas pedagógicas inclusivas. Marília: Cultura Acadêmica, 2012.

KAUFFEMAN, M. J. Classificação e categorização. In: KAUFFMAN, M. J.; LOPES, A. J. Pode a educação especial deixar de ser especial? Braga, Portugal: Psiquilíbrios, 2007. p. II-20.

LAUAND, G. B. do A.; MENDES, E. G. Fontes de informação sobre tecnologia assistiva para indivíduos com necessidades educacionais especiais. In: MENDES, E. G.; SILVA, M. Sala de aula interativa. Rio de Janeiro: Quartet, 2002.

THOMPSON, A. Comentário em foro virtual é a tecnologia matando habilidades de pensamento crítico. 2010. 